\title{
Glycemic variability in continuous glucose monitoring is inversely associated with baroreflex sensitivity in type 2 diabetes: a preliminary report
}

Daisuke Matsutani ${ }^{\dagger}$, Masaya Sakamoto ${ }^{*} \mathbb{C D}$, Hiroyuki luchi, Souichirou Minato, Hirofumi Suzuki, Yosuke Kayama, Norihiko Takeda, Ryuzo Horiuchi and Kazunori Utsunomiya

\begin{abstract}
Background: It is presently unclear whether glycemic variability (GV) is associated with baroreflex sensitivity (BRS), which is an early indicator of cardiovascular autonomic neuropathy. The present study is the first to examine the relationships between BRS and GV measured using continuous glucose monitoring (CGM).

Methods: This was a multicenter, prospective, open-label clinical trial. A total of 102 patients with type 2 diabetes were consecutively recruited for this study. GV was assessed by measuring the standard deviation (SD), glucose coefficient of variation (CV), and the mean amplitude of glycemic excursions (MAGE) during CGM. The BRS was analyzed from electrocardiogram and blood pressure recordings using the sequence method on the first day of hospitalization.

Results: A total of 94 patients (mean diabetes duration $9.7 \pm 9.6$ years, mean $\mathrm{HbA1c} 61.0 \pm 16.8 \mathrm{mmol} / \mathrm{mol}$ $[7.7 \pm 1.5 \%])$ were analyzed. In the univariate analysis, CGM-SD $(r=-0.375, p=0.000)$, CGM-CV $(r=-0.386, p=0.000)$, and MAGE $(r=-0.395, p=0.000)$ were inversely related to BRS. In addition to GV, the level of BRS correlated with the coefficient of variation in the R-R intervals (CVR-R) $(r=0.520, p=0.000)$, heart rate (HR) $(r=-0.310, p=0.002)$, cardioankle vascular index (CAVI) $(r=-0.326, p=0.001)$, age $(r=-0.519, p=0.000)$, and estimated glomerular filtration rate (eGFR) $(r=0.276, p=0.007)$. Multiple regression analysis showed that CGM-CV and MAGE were significantly related to a decrease in BRS. These findings remained after adjusting the BRS for age, sex, hypertension, dyslipidemia, HR, eGFR, CAVI, and CGM-mean glucose. Additionally, BRS was divided according to quartiles of the duration of diabetes (Q1-4). BRS decreased after a 2-year duration of diabetes independently of age and sex.
\end{abstract}

Conclusions: GV was inversely related to BRS independently of blood glucose levels in type 2 diabetic patients. Measurement of BRS may have the potential to predict CV events in consideration of GV.

Trial registration UMIN Clinical Trials Registry UMIN000025964, 28/02/2017

Keywords: Glycemic variability, Baroreflex sensitivity, Cardiovascular autonomic neuropathy, Cardiovascular disease, Continuous glucose monitoring, Type 2 diabetes

\footnotetext{
*Correspondence: m-sakamoto@umin.ac.jp

${ }^{\dagger}$ Daisuke Matsutani and Masaya Sakamoto contributed equally to this

study

Division of Diabetes, Metabolism and Endocrinology, Department

of Internal Medicine, 3-25-8, Nishi-Shinbashi, Minato-ku, Tokyo 105-8461,

Japan
} 


\section{Background}

Baroreflex sensitivity (BRS), which is a sensitive measure of cardiovascular autonomic neuropathy (CAN) in type 2 diabetic patients [1, 2], is associated with cardiovascular disease events [3-5]. Risk factors involved in the reduced BRS in type 2 diabetes have yet to be fully elucidated. Previously reported risk factors for reduced BRS include hyperglycemia, diabetic duration, older age, obesity, hypoadiponectinemia, arteriosclerosis, and hypertension [6-12]. Among risk factors, although chronic hyperglycemia is an important pathophysiological factor in reduced BRS, improved chronic hyperglycemia alone was not shown to improve CAN in type 2 diabetes [13, 14]. In addition to chronic hyperglycemia, increased glycemic variability (GV) may be an independent risk factor for developing CAN [15-19]. However, the relationship between GV and BRS has not been clarified. GV was previously evaluated by self-monitoring of blood glucose (SMBG) 7 times a day, mainly in insulin-treated patients. The recent clinical application of continuous glucose monitoring (CGM) and flash glucose monitoring has allowed detailed assessment of GV [20].

The present study is the first to examine the relationships between BRS and GV measured using CGM.

\section{Methods}

\section{Study participants}

This was a multicenter, prospective, open-label clinical trial. A total of 102 patients with type 2 diabetes (69 males and 33 females) were consecutively recruited from hospitalized patients at Jikei University School of
Medicine Hospital, Tokyo, Japan and Tsuruoka kyoritsu Hospital, Yamagata, Japan. Inclusion criteria were age $\geq 20$ years and the presence of type 2 diabetes diagnosed according to 2017 American Diabetes Association guidelines. Exclusion criteria were taking non-dihydropyridine calcium channel blockers, digitalis, or antipsychotics. Exclusion criteria also included arrhythmia, severe renal dysfunction (serum $\mathrm{Cr} \geq 2.5 \mathrm{mg} / \mathrm{dL}$ ), severe liver dysfunction (3X upper limit of normal), severe infection, severe trauma, pre- and post-operation, diabetic ketosis, diabetic coma, insulin-dependent diabetes mellitus, malignancy, myocardial infarction, heart failure, cerebral infarction within a half year, pregnancy, or heavy alcohol consumption.

Of the 102 recruited patients, 97 were included in the analysis after excluding 2 with arrhythmias, 2 patients who were taking antipsychotics, and 1 with a malignancy. Further excluded were 3 participants whose BRS was below the lower threshold. Finally, a total of 94 patients with type 2 diabetes (66 males and 28 females) were analyzed (Fig. 1).

All participants underwent blood tests, including those for fasting plasma glucose (FPG), HbA1c, estimated glomerular filtration rate (eGFR), high density lipoprotein-cholesterol (HDL-C), low density lipoprotein-cholesterol (LDL-C), and triglycerides. Clinical data (duration of diabetes, body mass index [BMI], systolic blood pressure [SBP], diastolic blood pressure [DBP], insulin therapy, use of an oral anti-diabetic drugs, lipid-lowering agents and anti-hypertensive agents, smoking experience) were obtained from

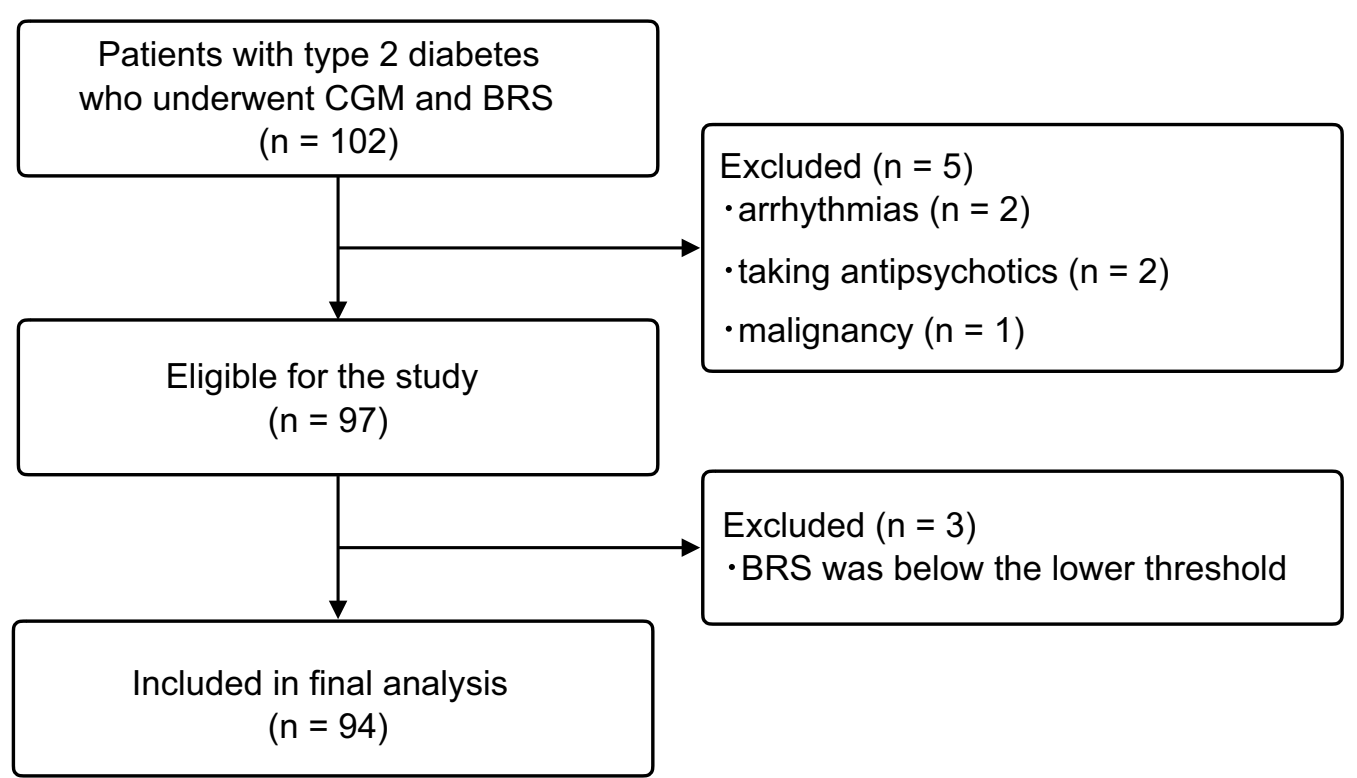

Fig. 1 Study population. Ninety-four participants were enrolled in this study. CGM continuous glucose monitoring, BRS baroreflex sensitivity 
medical records and a questionnaire. Dyslipidemia and hypertension were diagnosed based on Japanese guidelines. Dyslipidemia was defined as HDL-C $<40 \mathrm{mg} / \mathrm{dL}$, $\mathrm{LDL}-\mathrm{C} \geq 140 \mathrm{mg} / \mathrm{dL}$, and/or triglycerides $\geq 150 \mathrm{mg} /$ $\mathrm{dL})$ and/or taking at least one lipid-lowering agent. Hypertension was defined as SBP $\geq 140 \mathrm{mmHg}$ and/or $\mathrm{DBP} \geq 90 \mathrm{mmHg}$ and/or taking at least one anti-hypertensive agent. The study protocol was approved by the local ethics committee, and the study was conducted according to the principles of the Helsinki Declaration II. All patients were informed of the purpose of the study after which consent was obtained.

\section{Assessment of glycemic variability}

All study patients were monitored continuously with a continuous glucose monitor (ipro-2, Medtronic, Minneapolis, MN, USA) for $48 \mathrm{~h}$ beginning the first hospital day (Fig. 2). The monitor's sensor was inserted into abdominal subcutaneous adipose tissue and calibrated according to the standard Medtronic ipro-2 operating guidelines. During the monitoring, patients measured their blood glucose at least 4 times per day with a SMBG device (Medisafe FIT, Terumo, Tokyo, Japan). After $48 \mathrm{~h}$ of monitoring, the glucose profile and GV parameters were analyzed with computer software. $\mathrm{GV}$ was assessed by measuring the standard deviation $(\mathrm{SD})$, glucose coefficient of variation $(\mathrm{CV})$, and the mean amplitude of glycemic excursions (MAGE) during the CGM. CV was calculated by dividing the SD by the mean of the corresponding glucose readings, and the MAGE was calculated by measuring the arithmetic mean of the differences between consecutive peaks and nadirs, provided that the differences were greater than one SD of the mean glucose value. Patients continued anti-hyperglycemic therapy as usual and avoided glucose infusions during CGM.

\section{Assessment of baroreflex sensitivity}

BRS was evaluated on the first day of hospitalization (Fig. 2). Beat-to-beat BP was measured for $15 \mathrm{~min}$ after 15 min of supine rest by the spontaneous sequence method as the slope of the relationship between spontaneous changes in SBP and the pulse interval [21, 22]. Beat-to-beat $\mathrm{BP}$ was measured using the second and third fingers of the right hand by the vascular unloading technique (Task Force Monitor, CNSystems, Graz, Austria). The system was calibrated using a conventional noninvasive BP cuff wrapped around the left upper arm. Calibration was performed automatically every $2 \mathrm{~min}$. A standard 3-lead electrocardiogram (ECG) was used to record the heart rate (HR). For calculation of BRS, the relative changes in $\mathrm{BP}(\mathrm{mmHg})$ and the $\mathrm{R}-\mathrm{R}$ interval (ms), which is expressed as the distance between corresponding QRS complexes, were considered according to the sequence method with cut-off points of $1 \mathrm{mmHg}$ and $3 \mathrm{~ms}$, respectively.

\section{Assessment of the CV in the R-R intervals (CVR-R)}

The CVR-R was measured based on previously reported methods by the Cardio Star FCP-7431 (Fukuda Denshi, Tokyo, Japan) [23]. CVR-R was recorded by taking 100 samples of the HR on the first day of hospitalization (Fig. 2). Based on the mean R-R intervals (mRR) and the $\mathrm{R}-\mathrm{R}$ standard deviation (RR-SD), the CVR-R was calculated as RR-SD $/ \mathrm{mRR} \times 100(\%)$ (reference range $>2 \%$ ).

\section{Assessment of the cardio-ankle vascular index (CAVI)}

The CAVI was measured by the VaSera VS-3000N (Fukuda Denshi, Tokyo, Japan) on the first day of hospitalization (Fig. 2). With participants in the supine

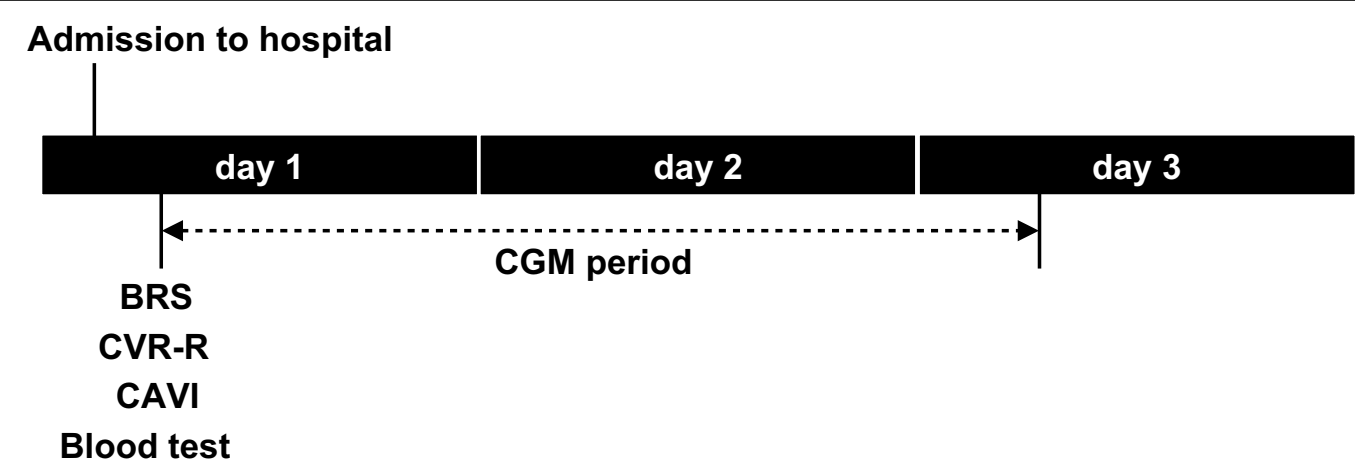

Fig. 2 Study protocol. On admission, a blood test was performed under fasting conditions. BRS, CVR-R, and CAVI were evaluated on the first day of hospitalization. Subcutaneous interstitial glucose levels were monitored over a period of 2 consecutive days using continuous glucose monitoring (CGM). BRS baroreflex sensitivity, CVR-R coefficient of variation in the R-R intervals, CAVI cardio-ankle vascular index 
position, BP was measured at the brachial artery, and heart beats were monitored by an ECG. The length from the aortic valve to the ankle and the time for the pulse wave to propagate from the heart to the ankle were measured. The principle of the CAVI formula and its calculation were described previously [24]. For statistical evaluation of the CAVI, mean values for the left and right sides were used.

\section{Statistical analyses}

Data analyses were performed using the Statistical Package for the Social Sciences 22.0 software (IBM, Armonk, NY, USA). Patient characteristics and results are presented as mean $\pm \mathrm{SD}$. Pearson's correlation analysis was used for single correlations. Multiple-linear regression was used to assess individual and cumulative effects of GV (CGM-SD, CGM-CV, and MAGE), age, sex, hypertension, dyslipidemia, HR, eGFR, CAVI, and CGM-mean glucose on BRS. Independent variables were selected based on previous studies pertaining to factors associated with low levels of BRS [10, 25-28]. Diabetes durations were divided into quartiles $(\mathrm{Q} 1<2, \mathrm{Q} 2 \geq 2$ to $<7, \mathrm{Q} 3 \geq 7$ to $<14, \mathrm{Q} 4 \geq 14$ years) (Tables 5,6 , Fig. 5). The analysis of variance (ANOVA) was used to compare BRS among participants according to quartiles of diabetes duration. The Jonckheere trend test was used to test for linear trends in BRS in relation to diabetes duration quartiles. In ANOVA, the Games-Howell post hoc test was also used to compare the BRS results among different diabetes duration groups. In the multivariate analysis, analysis of covariance (ANCOVA) was used to compare the coefficients of BRS among different diabetes duration groups with adjustment for age (years) and sex (male vs. female). In ANCOVA, the Bonferroni post hoc tests were also used to compare the BRS results among different diabetes duration groups. The Student's t test or the non-parametric Mann-Whitney U-test was used to compare the means of continuous variables. A $p<0.05$ was considered significant.

\section{Results}

\section{Baseline characteristics of study participants}

A total of 94 patients were analyzed. Clinical and anthropometric characteristics of the study participants are shown in Table 1. Baseline drug administration is shown in Table 2. The prevalence of study participants ever diagnosed with hypertension or dyslipidemia was 72 and $88 \%$, respectively. The mean age of participants was $62.1 \pm 11.9$ years, mean duration of diabetes was
Table 1 Baseline patient characteristics

\begin{tabular}{ll}
\hline Baseline data & \\
\hline No. of patients & 94 \\
Sex, male/female & $66 / 28$ \\
Age (years) & $62.1 \pm 11.9$ \\
Body mass index (kg/m²) & $26.2 \pm 5.0$ \\
Duration of diabetes (years) & $9.7 \pm 9.6$ \\
Fasting plasma glucose (mg/dL) & $141.8 \pm 36.4$ \\
HbA1c (mmol/mol) & $61.0 \pm 16.8$ \\
HbA1c (\%) & $7.7 \pm 1.5$ \\
Smoking, $n$ (\%) & $30(32)$ \\
Hypertension, $\mathrm{n}(\%)$ & $68(72)$ \\
Dyslipidemia, $\mathrm{n}(\%)$ & $83(88)$ \\
Blood pressure (mmHg) & \\
Systolic & $121.9 \pm 17.2$ \\
Diastolic & $76.5 \pm 9.9$ \\
Heart rate (beats/min) & $69.2 \pm 11.0$ \\
Lipid profile (mg/dL) & \\
Triglycerides & $150.2 \pm 87.0$ \\
LDL-cholesterol & $112.9 \pm 29.0$ \\
HDL-cholesterol & $50.4 \pm 15.3$ \\
eGFR (ml/min/1.73 m²) & $76.4 \pm 16.6$ \\
CGM parameters (mg/dL) & \\
Mean glucose & $156.7 \pm 31.6$ \\
SD & $35.1 \pm 13.4$ \\
CV & $22.4 \pm 7.5$ \\
MAGE & $88.2 \pm 32.2$ \\
CVS (ms-R (\%) & $9.0 \pm 4.5$ \\
CAVI & $2.9 \pm 1.4$ \\
\hline & $8.5 \pm 1.2$ \\
\hline
\end{tabular}

Values are mean \pm SD or no. (\%)

$L D L$ low density lipoprotein, $H D L$ high density lipoprotein, eGFR estimated glomerular filtration rate, CGM continuous glucose monitoring, SD standard deviation, $C V$ coefficient of variance, MAGE mean amplitude of glycemic excursions, $B R S$ baroreflex sensitivity, $C V R-R$ coefficient of variation in the $\mathrm{R}-\mathrm{R}$ intervals, CAVI cardio-ankle vascular index

$9.7 \pm 9.6$ years, and mean $\mathrm{HbA} 1 \mathrm{c}$ was $61.0 \pm 16.8 \mathrm{mmol} /$ mol $(7.7 \pm 1.5 \%)$. At baseline, $27 \%$ of patients were on sulfonylureas, $13 \%$ on insulin, $36 \%$ on renin-angiotensin-aldosterone system (RAAS) inhibitors (angiotensin-converting enzyme inhibitors and/or angiotensin receptor blockers), $34 \%$ on calcium-channel blockers, and $5 \%$ on beta-blockers, and $30 \%$ on a statins.

\section{Univariate correlates of BRS}

Correlation analysis showed that parameters of GV, such as the of CGM-SD $(r=-0.375, \quad p=0.000)$, 
Table 2 Baseline drug administration

\begin{tabular}{lc}
\hline Therapy & \\
\hline Oral anti-diabetic drugs, n (\%) & $69(73)$ \\
Metformin, n (\%) & $35(37)$ \\
Sulfonylureas, n (\%) & $25(27)$ \\
Thiazolidinediones, n (\%) & $10(11)$ \\
Glinides, n (\%) & $3(3)$ \\
DPP-4 inhibitors, n (\%) & $46(49)$ \\
a-glucosidase inhibitors, n (\%) & $5(5)$ \\
SGLT2 inhibitors, n (\%) & $11(12)$ \\
GLP-1 receptor agonists, n (\%) & $3(3)$ \\
Insulin, n (\%) & $12(13)$ \\
Anti-hypertensive agents, n (\%) & $45(48)$ \\
RAAS inhibitors, n (\%) & $34(36)$ \\
Calcium-channel blockers, n (\%) & $32(34)$ \\
Thiazides, n (\%) & $5(5)$ \\
Beta-blockers, n (\%) & $5(5)$ \\
Lipid-lowering agents, n (\%) & $32(34)$ \\
Statins, n (\%) & $28(30)$
\end{tabular}

Values are no. (\%)

DPP dipeptidyl peptidase-4, SGLT sodium glucose cotransporter, GLP glucagonlike peptide, RAAS renin-angiotensin-aldosterone system

CGM-CV $(r=-0.386, \quad p=0.000), \quad$ and MAGE $(r=-0.395, p=0.000)$, were significantly related to low levels of BRS (Fig. 3, Table 3). In addition to GV, the level of BRS correlated with CVR-R $(r=0.520, p=0.000)$, HR $(r=-0.310, p=0.002)$, CAVI $(r=-0.326, p=0.001)$, age $(r=-0.519, p=0.000)$, and eGFR $(r=0.276, p=0.007)$. However, CGM-mean glucose $(r=-0.099, p=0.341)$, FPG $(r=0.182, p=0.079)$, HbA1c $(r=0.250, p=0.015)$, $\operatorname{SBP}(r=-0.037, p=0.724)$, DBP $(r=-0.028, p=0.786)$, and BMI $(r=0.193, p=0.062)$ did not (Table 3, Fig. 4$)$.
Table 3 Univariate correlates of BRS

\begin{tabular}{|c|c|c|}
\hline Variables & $r$ & $p$ \\
\hline CGM-SD (mg/dL) & -0.375 & 0.000 \\
\hline CGM-CV (mg/dL) & -0.386 & 0.000 \\
\hline MAGE (mg/dL) & -0.395 & 0.000 \\
\hline CGM-mean glucose (mg/dL) & -0.099 & 0.341 \\
\hline $\mathrm{FPG}(\mathrm{mg} / \mathrm{dL})$ & 0.182 & 0.079 \\
\hline $\mathrm{HbA1c}(\mathrm{mmol} / \mathrm{mol})$ & 0.250 & 0.015 \\
\hline CVR-R (\%) & 0.520 & 0.000 \\
\hline HR (beats/min) & -0.310 & 0.002 \\
\hline $\mathrm{SBP}(\mathrm{mmHg})$ & -0.037 & 0.724 \\
\hline $\mathrm{DBP}(\mathrm{mmHg})$ & -0.028 & 0.786 \\
\hline CAVI & -0.326 & 0.001 \\
\hline Age (years) & -0.519 & 0.000 \\
\hline BMI $\left(\mathrm{kg} / \mathrm{m}^{2}\right)$ & 0.193 & 0.062 \\
\hline $\mathrm{eGFR}\left(\mathrm{mL} / \mathrm{min} / 1.73 \mathrm{~m}^{2}\right)$ & 0.276 & 0.007 \\
\hline Triglycerides (mg/dL) & 0.171 & 0.099 \\
\hline LDL-cholesterol (mg/dL) & 0.165 & 0.111 \\
\hline HDL-cholesterol (mg/dL) & -0.094 & 0.365 \\
\hline
\end{tabular}

BRS baroreflex sensitivity, CGM continuous glucose monitoring, $S D$ standard deviation, $C V$ coefficient of variance, MAGE mean amplitude of glycemic excursions, $F P G$ fasting plasma glucose, $C V R-R$ coefficient of variation in the $\mathrm{R}-\mathrm{R}$ intervals, $H R$ heart rate, $S B P$ systolic blood pressure, $D B P$ diastolic blood pressure, CAVI cardio-ankle vascular index, BMI body mass index, eGFR estimated glomerular filtration rate, $L D L$ low density lipoprotein, HDL high density lipoprotein

\section{Multivariate analysis of BRS}

Multiple regression analysis showed that CGM-CV and MAGE were inversely related to BRS. These findings remained after adjusting BRS for age, sex, hypertension, dyslipidemia, HR, eGFR, CAVI, and CGM-mean glucose. In addition to $\mathrm{GV}$, age, $\mathrm{HR}$, and CAVI were found to be predictive factors for BRS (Table 4).

\section{Comparisons of BRS according to duration of diabetes}

Figure 5 and Table 5 show the comparisons of BRS among participants with various durations of diabetes
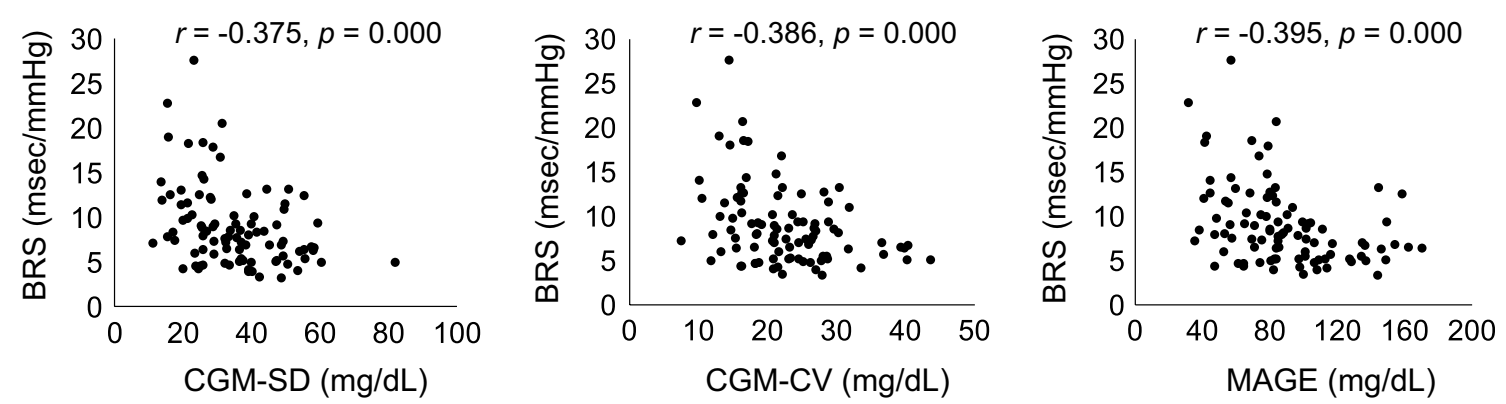

Fig. 3 Relationship between BRS and glycemic variability. BRS baroreflex sensitivity, CGM continuous glucose monitoring, SD standard deviation, CV coefficient of variance, MAGE mean amplitude of glycemic excursions 

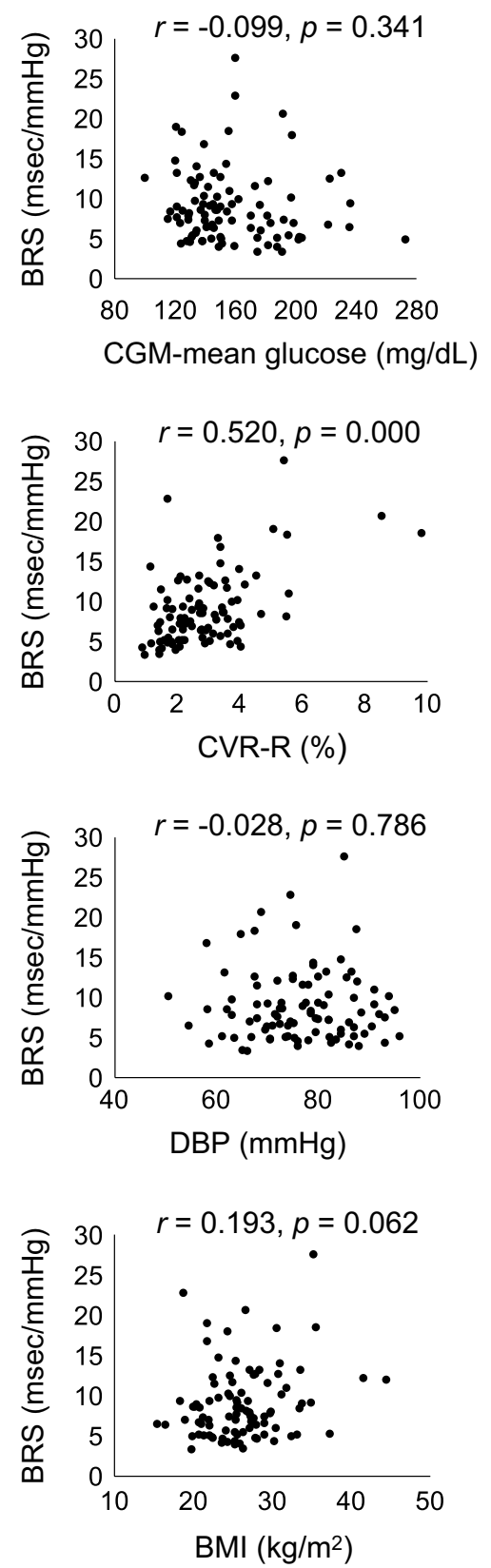
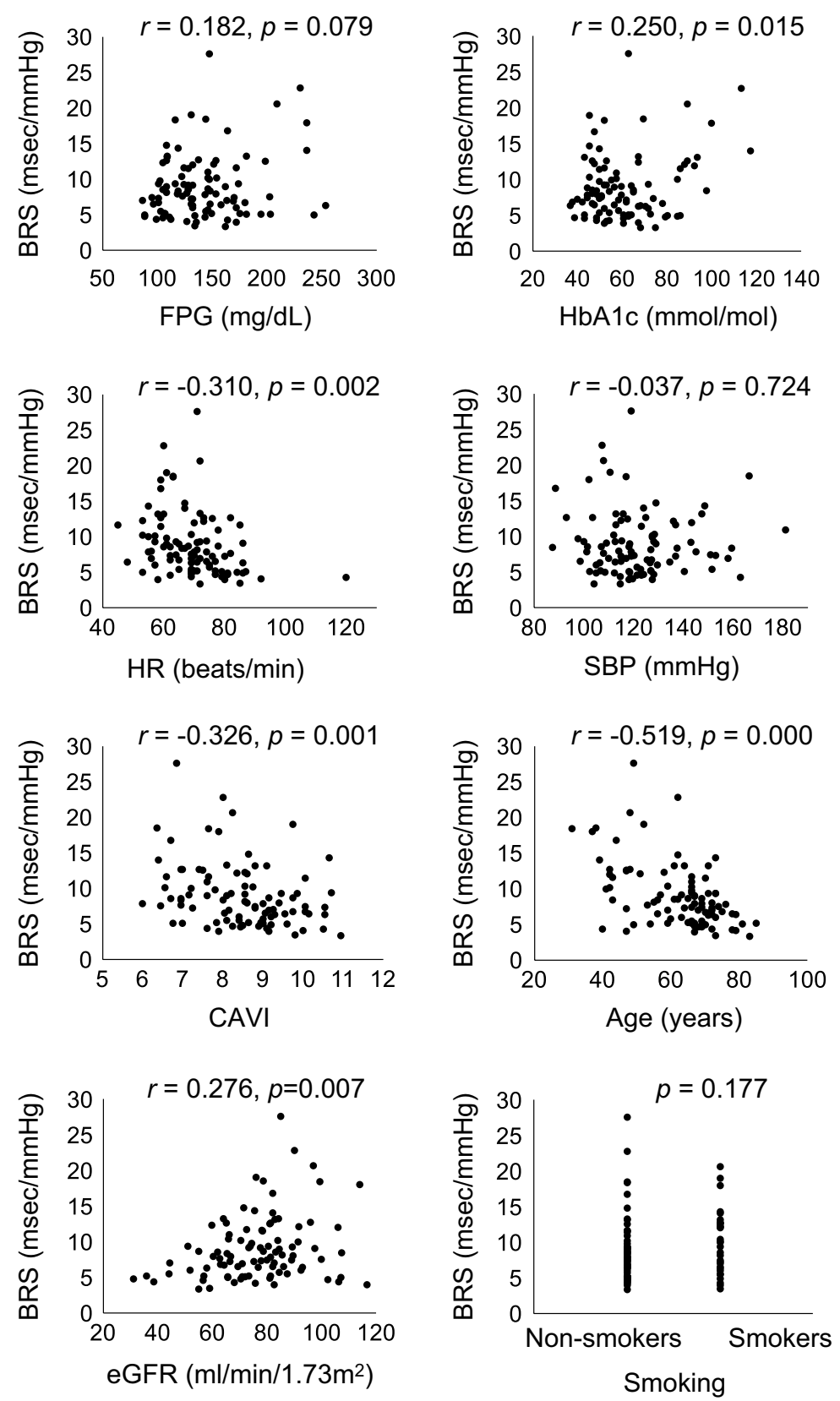

Fig. 4 Univariate correlates of BRS. BRS baroreflex sensitivity, CGM continuous glucose monitoring, FPG fasting plasma glucose, CVR-R coefficient of variation in the R-R intervals, HR heart rate, SBP systolic blood pressure, DBP diastolic blood pressure, CAVI cardio-ankle vascular index, BMI body mass index, eGFR estimated glomerular filtration rate 
Table 4 Multiple regression analysis of BRS

\begin{tabular}{|c|c|c|c|c|}
\hline \multirow[t]{2}{*}{ Dependent variables } & \multicolumn{2}{|l|}{ Model 1} & \multicolumn{2}{|l|}{ Model 2} \\
\hline & $\beta$ & $p$ & $\beta$ & $p$ \\
\hline \multicolumn{5}{|l|}{ (a) } \\
\hline CGM-SD (mg/dL) & -0.218 & 0.051 & -0.336 & 0.004 \\
\hline Age (years) & -0.435 & 0.000 & - & - \\
\hline Sex (male/female) & -0.029 & 0.731 & -0.061 & 0.506 \\
\hline Hypertension & -0.073 & 0.418 & -0.087 & 0.369 \\
\hline Dyslipidemia & -0.183 & 0.038 & -0.166 & 0.080 \\
\hline Heart rate (beats/min) & -0.259 & 0.004 & -0.244 & 0.012 \\
\hline $\mathrm{eGFR}\left(\mathrm{mL} / \mathrm{min} / 1.73 \mathrm{~m}^{2}\right)$ & 0.035 & 0.714 & 0.138 & 0.160 \\
\hline CAVI & - & - & -0.216 & 0.028 \\
\hline CGM-mean glucose (mg/dL) & 0.119 & 0.240 & 0.199 & 0.066 \\
\hline \multicolumn{5}{|l|}{ (b) } \\
\hline CGM-CV (mg/dL) & -0.206 & 0.032 & -0.304 & 0.002 \\
\hline Age (years) & -0.427 & 0.000 & - & - \\
\hline Sex (male/female) & -0.031 & 0.711 & -0.063 & 0.492 \\
\hline Hypertension & -0.071 & 0.428 & -0.084 & 0.385 \\
\hline Dyslipidemia & -0.184 & 0.036 & -0.166 & 0.077 \\
\hline Heart rate (beats/min) & -0.257 & 0.004 & -0.243 & 0.012 \\
\hline eGFR (mL/min/1.73 m²) & 0.042 & 0.657 & 0.149 & 0.125 \\
\hline CAVI & - & - & -0.207 & 0.035 \\
\hline CGM-mean glucose (mg/dL) & 0.012 & 0.889 & 0.034 & 0.721 \\
\hline \multicolumn{5}{|l|}{ (c) } \\
\hline MAGE (mg/dL) & -0.227 & 0.036 & -0.346 & 0.002 \\
\hline Age (years) & -0.414 & 0.000 & - & - \\
\hline Sex (male/female) & -0.020 & 0.809 & -0.044 & 0.630 \\
\hline Hypertension & -0.088 & 0.328 & -0.110 & 0.256 \\
\hline Dyslipidemia & -0.165 & 0.055 & -0.139 & 0.131 \\
\hline Heart rate (beats/min) & -0.274 & 0.002 & -0.269 & 0.005 \\
\hline $\mathrm{eGFR}\left(\mathrm{mL} / \mathrm{min} / 1.73 \mathrm{~m}^{2}\right)$ & 0.035 & 0.712 & 0.135 & 0.166 \\
\hline CAVI & - & - & -0.179 & 0.074 \\
\hline CGM-mean glucose (mg/dL) & 0.119 & 0.231 & 0.192 & 0.069 \\
\hline
\end{tabular}

The dependent variable was BRS, and the independent variables were Model 1 and Model 2. Model 1: adjustment for GV, age, sex, hypertension, dyslipidemia, heart rate, eGFR, and CGM-mean glucose; Model 2: adjustment for GV, sex, hypertension, dyslipidemia, heart rate, eGFR, CAVI, and CGM-mean glucose: GV was (a) CGM-SD, (b) CGM-CV, and (c) MAGE. Model 1 (a) R-squared 0.414, adjusted R-squared 0.359; (b) R-squared 0.420, adjusted R-squared 0.365; (c) R-squared 0.418, adjusted R-squared 0.364; Model 2 (a) R-squared 0.321, adjusted R-squared 0.257, (b) R-squared 0.328, adjusted R-squared 0.264, (c) R-squared 0.329, adjusted R-squared 0.266

BRS baroreflex sensitivity, CGM continuous glucose monitoring, SD standard deviation, $C V$ coefficient of variance, MAGE mean amplitude of glycemic excursions, eGFR estimated glomerular filtration rate, CAVI cardio-ankle vascular index

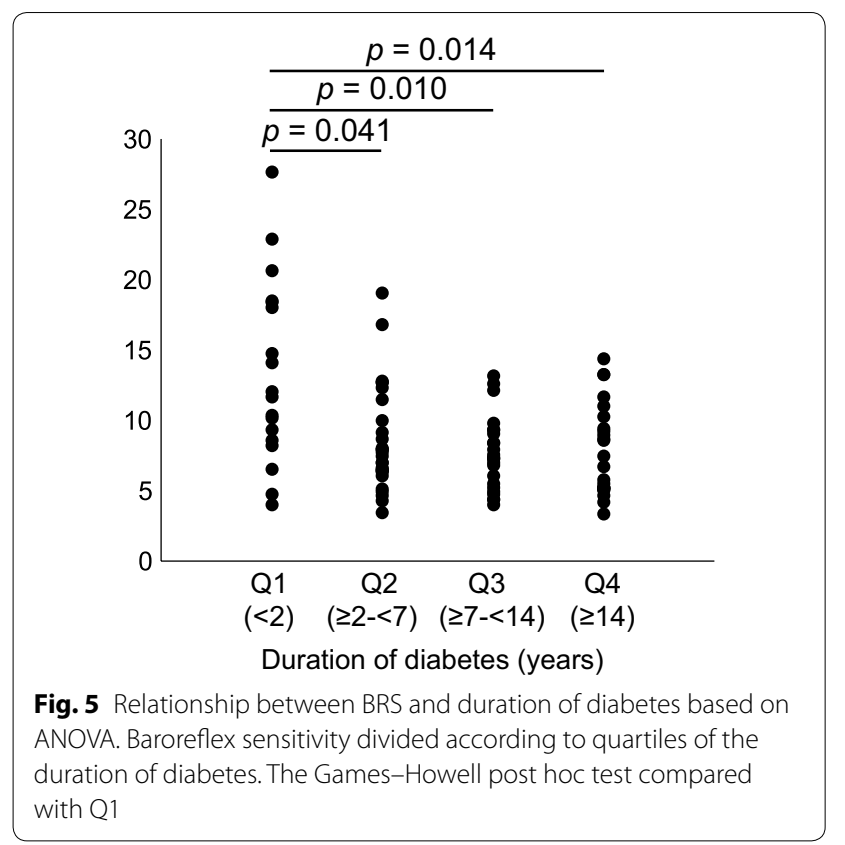

according to quartiles based on ANOVA. There was a significant difference in BRS among these four groups. The results were then analyzed by the Games-Howell post hoc test. The Q2 $(p=0.041), \mathrm{Q} 3(p=0.010)$, and $\mathrm{Q} 4(p=0.014)$ groups had reduced BRS in comparison with the Q1 group. This observation was confirmed by the Jonckheere trend test: BRS $(p=0.005)$ was significantly correlated with the quartiles of diabetes duration. For the multivariate analysis, Table 6 shows the comparisons of BRS among participants with various quartiles of diabetes duration based on ANCOVA. The results were then analyzed by the Bonferroni post hoc test.

After adjustment for age and sex, the Q2 $(p=0.012)$, Q3 $(p=0.003)$, and Q4 $(p=0.030)$ groups had significantly reduced BRS compared with the Q1 group.

\section{Comparisons of BRS according to various subgroups}

No difference existed in BRS between hypertensive and normotensive participants $(8.5 \pm 4.4$ vs. $10.4 \pm 4.6 \mathrm{~ms} /$ $\mathrm{mmHg}, p=0.056$ ) (Additional file 1: Tables S1 and S2), 
Table 5 Comparisons of BRS according to duration of diabetes based on ANOVA

\begin{tabular}{|c|c|c|c|c|c|c|}
\hline Diabetes duration (quartiles) & $\begin{array}{l}\text { Q1 (<2) } \\
(n=18)\end{array}$ & $\begin{array}{l}\mathrm{Q} 2(\geq 2 \text { to }<7) \\
(\mathrm{n}=28)\end{array}$ & $\begin{array}{l}Q 3(\geq 7 \text { to }<14) \\
(n=24)\end{array}$ & $\begin{array}{l}\mathrm{Q} 4(\geq 14) \\
(n=24)\end{array}$ & $\begin{array}{l}\text { ANOVA } \\
p \text { value }\end{array}$ & $\begin{array}{l}\text { Test for trend } \\
p \text { value }\end{array}$ \\
\hline $\mathrm{BRS}(\mathrm{ms} / \mathrm{mmHg})$ & $13.3 \pm 6.5$ & $8.5 \pm 3.7^{*}$ & $7.6 \pm 2.6^{*}$ & $7.7 \pm 3.2^{*}$ & 0.010 & 0.005 \\
\hline$p$ value & & 0.041 & 0.010 & 0.014 & & \\
\hline $\mathrm{HbA} 1 \mathrm{c}(\mathrm{mmol} / \mathrm{mol})$ & $69 \pm 25.6$ & $57.2 \pm 13.6$ & $58.8 \pm 12.7$ & $61.7 \pm 14.6$ & & \\
\hline $\mathrm{HbA} 1 \mathrm{c}(\%)$ & $8.5 \pm 2.3$ & $7.4 \pm 1.2$ & $7.5 \pm 1.2$ & $7.8 \pm 1.3$ & & \\
\hline CGM-mean glucose (mg/dL) & $152.1 \pm 23.9$ & $153.1 \pm 36.1$ & $162.1 \pm 32.6$ & $159.2 \pm 31.8$ & & \\
\hline CGM-SD (mg/dL) & $30.7 \pm 12.2$ & $33 \pm 12.1$ & $33.5 \pm 13.3$ & $42.6 \pm 13.7$ & & \\
\hline CGM-CV (mg/dL) & $20.3 \pm 8.1$ & $21.8 \pm 7.8$ & $20.2 \pm 5.6$ & $26.7 \pm 6.9$ & & \\
\hline MAGE (mg/dL) & $76.5 \pm 30.6$ & $85.7 \pm 30.2$ & $85.4 \pm 34.9$ & $102.6 \pm 29.7$ & & \\
\hline
\end{tabular}

Values are mean $\pm S D$. BRS was divided according to quartiles of diabetes duration. The Games-Howell post hoc test compared with Q1: * $p<0.05$

Table 6 Comparison of BRS according to diabetes duration based on ANCOVA

\begin{tabular}{|c|c|c|c|c|c|}
\hline Diabetes duration (quartiles) & $\begin{array}{l}\text { Q1 (<2) } \\
(n=18)\end{array}$ & $\begin{array}{l}\mathrm{Q} 2(\geq 2 \text { to }<7) \\
(n=28)\end{array}$ & $\begin{array}{l}Q 3(\geq 7 \text { to }<14) \\
(n=24)\end{array}$ & $\begin{array}{l}\mathrm{Q} 4(\geq 14) \\
(n=24)\end{array}$ & $\begin{array}{l}\text { ANCOVA } \\
p \text { value }\end{array}$ \\
\hline $\mathrm{BRS}(\mathrm{ms} / \mathrm{mmHg})$ & $12.1 \pm 0.9$ & $8.3 \pm 0.8^{*}$ & $7.6 \pm 0.8^{*}$ & $8.1 \pm 1.0^{*}$ & 0.003 \\
\hline$p$ value & & 0.012 & 0.003 & 0.03 & \\
\hline $\mathrm{HbA1c}(\mathrm{mmol} / \mathrm{mol})$ & $69 \pm 25.6$ & $57.2 \pm 13.6$ & $58.8 \pm 12.7$ & $61.7 \pm 14.6$ & \\
\hline HbA1c (\%) & $8.5 \pm 2.3$ & $7.4 \pm 1.2$ & $7.5 \pm 1.2$ & $7.8 \pm 1.3$ & \\
\hline CGM-mean glucose (mg/dL) & $152.1 \pm 23.9$ & $153.1 \pm 36.1$ & $162.1 \pm 32.6$ & $159.2 \pm 31.8$ & \\
\hline CGM-SD (mg/dL) & $30.7 \pm 12.2$ & $33 \pm 12.1$ & $33.5 \pm 13.3$ & $42.6 \pm 13.7$ & \\
\hline CGM-CV (mg/dL) & $20.3 \pm 8.1$ & $21.8 \pm 7.8$ & $20.2 \pm 5.6$ & $26.7 \pm 6.9$ & \\
\hline MAGE (mg/dL) & $76.5 \pm 30.6$ & $85.7 \pm 30.2$ & $85.4 \pm 34.9$ & $102.6 \pm 29.7$ & \\
\hline
\end{tabular}

Values for BRS are adjusted mean $\pm S E$, all other values are mean $\pm S D$. BRS was divided according to quartiles of diabetes duration. Adjustment for age (years) and sex (male vs. female). The Bonferroni post hoc test compared with Q1: ${ }^{*} p<0.05$

those with dyslipidemia and normal lipid values $(8.8 \pm 4.4$ vs. $10.0 \pm 5.8 \mathrm{~ms} / \mathrm{mmHg}, p=0.424)$, and the presence or absence of a smoking history $(9.9 \pm 4.5$ vs. $8.5 \pm 4.5 \mathrm{~ms} /$ $\mathrm{mmHg}, p=0.177)$. Use of sulfonylurea was associated with low levels of BRS compared with its non-use (sulfonylurea use vs. non-use: $7.1 \pm 3.2$ vs. $9.7 \pm 4.8 \mathrm{~ms} / \mathrm{mmHg}$, $p=0.015$ ) (Table 7). The GV in patients taking sulfonylurea was larger than in those who did not (sulfonylurea use vs. non-use: CGM-SD $41.9 \pm 14.0$ vs. $32.7 \pm 12.5 \mathrm{mg} /$ $\mathrm{dL}, p=0.003$; CGM-CV $25.5 \pm 8.6$ vs. $21.3 \pm 6.8 \mathrm{mg} /$ $\mathrm{dL}, p=0.015$; MAGE $102.8 \pm 30.2$ vs. $82.9 \pm 31.5 \mathrm{mg} /$ $\mathrm{dL}, p=0.007$ ) (Additional file 1: Table S3). There was no significant relationship between the mean BRS and the use of insulin, RAAS inhibitors (angiotensin-convertingenzyme inhibitors and/or angiotensin II receptor blockers), calcium-channel blockers, beta-blockers, or statins (Table 7).

\section{Discussion}

This is the first study of type 2 diabetic patients to examine the relationship between BRS and GV as measured by CGM.

Results showed that CGM-SD, CGM-CV, and MAGE were inversely related to BRS. However, no inverse correlations were found between BRS and the levels of CGMmean glucose, FPG, and HbA1c. The multiple regression analysis also showed that CGM-CV and MAGE were predictors of BRS independent of age, sex, hypertension, dyslipidemia, HR, eGFR, CAVI, and CGM-mean glucose.

As in previous reports, our analysis also showed that age, HR, and CAVI were predictors of BRS [10, 29]. Additionally, BRS decreased after a 2-year duration of diabetes. Further analysis of the association of oral antidiabetic drugs with BRS indicated that sulfonylurea was associated with reduced BRS. 
Table 7 Comparison of BRS in various subgroups

\begin{tabular}{|c|c|c|c|}
\hline $\begin{array}{l}\text { Condition } \\
\text { or therapy }\end{array}$ & No. (\%) & $\mathrm{BRS}(\mathrm{ms} / \mathrm{mmHg})$ & $\begin{array}{l}p \text { value } \\
\text { for interaction }\end{array}$ \\
\hline \multicolumn{4}{|c|}{ Hypertension } \\
\hline Yes & $68(72)$ & $8.5 \pm 4.4$ & \multirow[t]{2}{*}{0.056} \\
\hline No & $26(28)$ & $10.4 \pm 4.6$ & \\
\hline \multicolumn{4}{|c|}{ Hyperlipidemia } \\
\hline Yes & $83(88)$ & $8.8 \pm 4.4$ & \multirow[t]{2}{*}{0.424} \\
\hline No & $11(12)$ & $10.0 \pm 5.8$ & \\
\hline \multicolumn{4}{|l|}{ Smoking } \\
\hline Yes & $30(32)$ & $9.9 \pm 4.5$ & \multirow[t]{2}{*}{0.177} \\
\hline No & $64(68)$ & $8.5 \pm 4.5$ & \\
\hline \multicolumn{4}{|c|}{ Sulfonylurea use } \\
\hline Yes & $25(27)$ & $7.1 \pm 3.2$ & \multirow[t]{2}{*}{0.015} \\
\hline No & $69(73)$ & $9.7 \pm 4.8$ & \\
\hline \multicolumn{4}{|l|}{ Insulin use } \\
\hline Yes & $12(13)$ & $9.7 \pm 5.6$ & \multirow[t]{2}{*}{0.556} \\
\hline No & $82(87)$ & $8.9 \pm 4.4$ & \\
\hline \multicolumn{4}{|c|}{ RAAS inhibitor use } \\
\hline Yes & $34(36)$ & $8.6 \pm 4.8$ & \multirow[t]{2}{*}{0.284} \\
\hline No & $60(64)$ & $9.2 \pm 4.4$ & \\
\hline \multicolumn{4}{|c|}{ Calcium-channel blocker use } \\
\hline Yes & $32(34)$ & $8.5 \pm 4.8$ & \multirow[t]{2}{*}{0.258} \\
\hline No & $62(66)$ & $9.2 \pm 4.4$ & \\
\hline \multicolumn{4}{|c|}{ Beta-blocker use } \\
\hline Yes & $5(5)$ & $8.4 \pm 3.7$ & \multirow[t]{2}{*}{0.788} \\
\hline No & $89(95)$ & $9.0 \pm 4.6$ & \\
\hline \multicolumn{4}{|l|}{ Statin use } \\
\hline Yes & $28(30)$ & $9.0 \pm 5.0$ & \multirow[t]{2}{*}{0.138} \\
\hline No & $66(70)$ & $9.0 \pm 4.4$ & \\
\hline
\end{tabular}

Values are mean $\pm \mathrm{SD}$ or no. (\%)

$B R S$ baroreflex sensitivity, RAAS renin-angiotensin-aldosterone system

Although it was previously reported that BRS was decreased in type 2 diabetic patients $[6,30]$, the detailed mechanism has not been elucidated. In this study, GV, which is an independent risk factor for developing CV events [31-36], was inversely related to BRS independent of CGM-mean glucose. This result suggests that GV is involved in the reduced BRS in type 2 diabetes rather than chronic hyperglycemia. Our study further supports existing data showing that individuals with impaired glucose tolerance (IGT) had reduced BRS compared to individuals with normal glucose tolerance (NGT), while it was previously shown that those with impaired fasting glycemia (IFG) did not have reduced BRS $[19,37]$. On the other hand, oral anti-diabetic drugs have a relatively large effect on GV. In this study, patients taking sulfonylurea had larger GV than those who did not (sulfonylurea use vs. non-use:
CGM-SD $41.9 \pm 14.0$ vs. $32.7 \pm 12.5 \mathrm{mg} / \mathrm{dL}, p=0.003$; CGM-CV $25.5 \pm 8.6$ vs. $21.3 \pm 6.8 \mathrm{mg} / \mathrm{dL}, p=0.015$; MAGE $102.8 \pm 30.2$ vs. $82.9 \pm 31.5 \mathrm{mg} / \mathrm{dL}, p=0.007)$ (Additional file 1: Table S3). Furthermore, sulfonylureas were associated with reduced BRS $(p=0.015)$. It was reported that increased blood levels of insulin are also involved in reduced BRS [38]. Although the present study did not examine insulin levels, increased insulin levels may explain this phenomenon.

The following findings suggested that GV causes the reduced BRS by increasing oxidative stress and inducing endothelial dysfunction independently of chronic hyperglycemia: (1) GV increases oxidative stress [3941] and oxidative stress causes neuropathy [42, 43]; and (2) GV induces endothelial dysfunction [40, 41] and endothelial dysfunction causes neuropathy [44]. In addition to GV, our study showed that CAVI was independently correlated with BRS. Although it was reported that arteriosclerosis evaluated by intimamedia thickness or pulse wave velocity was involved in the reduced BRS [11, 27], this is the first report showing the relationship between CAVI and BRS.

The point during the course of diabetes at which BRS reduction begins to occur remains controversial [45]. We found that BRS began to decrease in patients after a relatively short duration of diabetes. In patients with type 2 diabetes of a short duration, increased GV caused by postprandial hyperglycemia is the predominant pathophysiological feature [46, 47]. Therefore, in our patients with diabetes of a short duration, an increased GV may have led to an early reduction in BRS.

This study has three notable limitations. First, the cross-sectional design without a control group does not allow for causal relationships to be identified. Hence, the observed associations may only serve as hypothesis generating. Further prospective studies are necessary to clarify causal relationships. Second, although BRS has been reported to decrease with the progression of CAN, the present study excluded patients whose BRS was less than the lower threshold. Moreover, although this study used the sequence method, it did not use other traditional methods. Third, the duration of hypertension or dyslipidemia was not taken into consideration.

\section{Conclusions}

GV was inversely related to BRS independently of blood glucose levels in type 2 diabetic patients. Although further prospective studies are necessary to clarify the causal relationship, these results may suggest that $\mathrm{GV}$ is an important risk factor affecting BRS. 


\section{Additional file}

Additional file 1: Table S1. Comparison of clinical characteristics among subjects with hypertensive and normotensive. Table S2. Univariate correlates of BRS in subjects with hypertensive and normotensive. Table S3. Comparison of BRS in subgroups

\section{Abbreviations}

BRS: baroreflex sensitivity; CAN: cardiovascular autonomic neuropathy; CAVI: cardio-ankle vascular index; CGM: continuous glucose monitoring; CVD: cardiovascular disease; CVR-R: coefficient of variation in the R-R intervals; GV: glycemic variability.

\section{Authors' contributions}

DM and MS contributed to the study design, data acquisition, and data analysis and wrote the manuscript. HI contributed to the study design. SM, HS, $Y K, N T, R H$, and KU reviewed and edited the intellectual content. All authors gave final approval for this version to be published. The funder had no role in study design, analysis, interpretation of data, writing of the manuscript, and the decision to submit the manuscript for publication. All authors read and approved the final manuscript.

\section{Acknowledgements}

None.

\section{Competing interests}

The authors of this manuscript have the following competing interests: M.S. has participated in speaker's bureaus/advisory panels for Sanofi, DaiichiSankyo, Astellas, and Tanabe-Mitsubishi. N.T. has received a research grant and support from Daiichi-Sankyo and Otsuka Pharmaceutical and has participated in speaker's bureaus organized by Daiichi-Sankyo and MSD. K.U. has received research support from Terumo, Kowa, Taisho, Arkray, Kyowa Kirin, MSD, Astellas, Boehringer Ingelheim, Ono, Novo Nordisk, Kissei and Tanabe-Mitsubishi and has participated in speaker's bureau/advisory panels for Astellas, Astra Zeneca, Kowa, MSD, Eli Lilly, Taisho, Novo Nordisk and Sanofi. The other authors have no competing interests to declare.

\section{Availability of data and materials}

The datasets used and/or analyzed during the current study are available from the corresponding author on reasonable request.

\section{Consent for publication}

Not applicable.

\section{Ethics approval and consent to participate}

The study protocol was approved by the local ethics committee, and the study was conducted according to the principles of the Helsinki Declaration II. All patients were informed of the purpose of the study after which consent was obtained.

\section{Funding}

No specific funding was received for the study.

\section{Publisher's Note}

Springer Nature remains neutral with regard to jurisdictional claims in published maps and institutional affiliations.

Received: 31 December 2017 Accepted: 1 March 2018

Published online: 07 March 2018

\section{References}

1. Frattola A, Parati G, Gamba P, Paleari F, Mauri G, Di Rienzo M, Castiglioni P, Mancia G. Time and frequency domain estimates of spontaneous baroreflex sensitivity provide early detection of autonomic dysfunction in diabetes mellitus. Diabetologia. 1997;40(12):1470-5.

2. Ziegler D, Laude D, Akila F, Elghozi JL. Time- and frequency-domain estimation of early diabetic cardiovascular autonomic neuropathy. Clin Auton Res. 2001;11(6):369-76.

3. La Rovere MT, Specchia G, Mortara A, Schwartz PJ. Baroreflex sensitivity, clinical correlates, and cardiovascular mortality among patients with a first myocardial infarction. A prospective study. Circulation. 1988:78(4):816-24.

4. La Rovere MT, Pinna GD, Hohnloser SH, Marcus Fl, Mortara A, Nohara R, Bigger JT Jr, Camm AJ, Schwartz PJ. Baroreflex sensitivity and heart rate variability in the identification of patients at risk for lifethreatening arrhythmias: implications for clinical trials. Circulation. 2001;103(16):2072-7.

5. Spallone V, Ziegler D, Freeman R, Bernardi L, Frontoni S, Pop-Busui R, Stevens M, Kempler P, Hilsted J, Tesfaye S, et al. Cardiovascular autonomic neuropathy in diabetes: clinical impact, assessment, diagnosis, and management. Diabetes/Metab Res Rev. 2011;27(7):639-53.

6. Rowaiye OO, Jankowska EA, Ponikowska B. Baroreceptor sensitivity and diabetes mellitus. Cardiol J. 2013;20(5):453-63.

7. Takahashi N, Anan F, Nakagawa M, Yufu K, Shinohara T, Tsubone T, Goto K, Masaki T, Katsuragi I, Tanaka K, et al. Hypoadiponectinemia in type 2 diabetes mellitus in men is associated with sympathetic overactivity as evaluated by cardiac 1231-metaiodobenzylguanidine scintigraphy. Metabolism. 2007:56(7):919-24.

8. Hansen CS, Vistisen D, Jorgensen ME, Witte DR, Brunner EJ, Tabak AG, Kivimaki M, Roden M, Malik M, Herder C. Adiponectin, biomarkers of inflammation and changes in cardiac autonomic function: Whitehall II study. Cardiovasc Diabetol. 2017;16(1):153.

9. Ziegler D, Strom A, Kupriyanova Y, Bierwagen A, Bonhof GJ, Bodis K, Mussig K, Szendroedi J, Bobrov P, Markgraf DF, et al. Association of lower cardiovagal tone and baroreflex sensitivity with higher liver fat content early in type 2 diabetes. J Clin Endocrinol Metab. 2017. https://doi. org/10.1210/jc.2017-02294.

10. Kardos A, Watterich G, de Menezes R, Csanady M, Casadei B, Rudas L. Determinants of spontaneous baroreflex sensitivity in a healthy working population. Hypertension. 2001;37(3):911-6.

11. Tomiyama H, Matsumoto C, Kimura K, Odaira M, Shiina K, Yamashina A. Pathophysiological contribution of vascular function to baroreflex regulation in hypertension. Circ J. 2014;78(6):1414-9.

12. Dalla Pozza R, Bechtold S, Bonfig W, Putzker S, Kozlik-Feldmann R, Schwarz HP, Netz H. Impaired short-term blood pressure regulation and autonomic dysbalance in children with type 1 diabetes mellitus. Diabetologia. 2007;50(12):2417-23

13. Duckworth W, Abraira C, Moritz T, Reda D, Emanuele N, Reaven PD, Zieve FJ, Marks J, Davis SN, Hayward R, et al. Glucose control and vascular complications in veterans with type 2 diabetes. N Engl J Med. 2009;360(2):129-39.

14. Azad N, Emanuele NV, Abraira C, Henderson WG, Colwell J, Levin SR, Nuttall FQ, Comstock JP, Sawin CT, Silbert C, et al. The effects of intensive glycemic control on neuropathy in the VA cooperative study on type II diabetes mellitus (VA CSDM). J Diabetes Complicat. 1999;13(5-6):307-13.

15. Xu W, Zhu Y, Yang X, Deng H, Yan J, Lin S, Yang H, Chen H, Weng J. Glycemic variability is an important risk factor for cardiovascular autonomic neuropathy in newly diagnosed type 2 diabetic patients. Int J Cardiol. 2016;215:263-8.

16. Jun JE, Jin SM, Baek J, Oh S, Hur KY, Lee MS, Lee MK, Kim JH. The association between glycemic variability and diabetic cardiovascular autonomic neuropathy in patients with type 2 diabetes. Cardiovasc Diabetol. 2015; 14:70

17. Jun JE, Lee SE, Lee YB, Ahn JY, Kim G, Jin SM, Hur KY, Lee MK, Kim JH. Glycated albumin and its variability as an indicator of cardiovascular autonomic neuropathy development in type 2 diabetic patients. Cardiovasc Diabetol. 2017:16(1):127.

18. Shimabukuro M, Tanaka A, Sata M, Dai K, Shibata Y, Inoue Y, Ikenaga H, Kishimoto S, Ogasawara K, Takashima A, et al. alpha-Glucosidase inhibitor miglitol attenuates glucose fluctuation, heart rate variability and sympathetic activity in patients with type 2 diabetes and acute coronary syndrome: a multicenter randomized controlled (MACS) study. Cardiovasc Diabetol. 2017;16(1):86. 
19. Wu JS, Lu FH, Yang YC, Chang SH, Huang YH, Chen JJ, Chang CJ. Impaired baroreflex sensitivity in subjects with impaired glucose tolerance, but not isolated impaired fasting glucose. Acta Diabetol. 2014;51(4):535-41.

20. Chon $\mathrm{S}$. How can we easily measure glycemic variability in diabetes mellitus? Diabetes Metab J. 2015;39(2):114-6.

21. La Rovere MT, Pinna GD, Raczak G. Baroreflex sensitivity: measurement and clinical implications. Ann Noninvasive Electrocardiol. 2008:13(2):191-207.

22. Parlow J, Viale JP, Annat G, Hughson R, Quintin L. Spontaneous cardiac baroreflex in humans. Comparison with drug-induced responses. Hypertension. 1995;25(5):1058-68.

23. Kageyama S, Taniguchi I, Tanaka S, Tajima N, Saito N, Ikeda Y, Abe M. A critical level of diabetic autonomic neuropathy. Tohoku J Exp Med. 1983;141(Suppl):479-83.

24. Shirai K, Hiruta N, Song M, Kurosu T, Suzuki J, Tomaru T, Miyashita Y, Saiki A, Takahashi M, Suzuki K, et al. Cardio-ankle vascular index (CAVI) as a novel indicator of arterial stiffness: theory, evidence and perspectives. J Atheroscler Thromb. 2011;18(11):924-38.

25. Lantelme P, Khettab F, Custaud MA, Rial MO, Joanny C, Gharib C, Milon H. Spontaneous baroreflex sensitivity: toward an ideal index of cardiovascular risk in hypertension? J Hypertens. 2002;20(5):935-44.

26. Kaur M, Chandran DS, Jaryal AK, Bhowmik D, Agarwal SK, Deepak KK. Baroreflex dysfunction in chronic kidney disease. World J Nephrol. 2016;5(1):53-65.

27. Gianaros PJ, Jennings JR, Olafsson GB, Steptoe A, Sutton-Tyrrell K, Muldoon MF, Manuck SB. Greater intima-media thickness in the carotid bulb is associated with reduced baroreflex sensitivity. Am J Hypertens. 2002;15(6):486-91.

28. Pierce GL, Harris SA, Seals DR, Casey DP, Barlow PB, Stauss HM. Estimated aortic stiffness is independently associated with cardiac baroreflex sensitivity in humans: role of ageing and habitual endurance exercise. J Hum Hypertens. 2016;30(9):513-20.

29. Reimann M, Rudiger H, Weiss N, Ziemssen T. Acute hyperlipidemia but not hyperhomocysteinemia impairs reflex regulation of the cardiovascular system. Atheroscler Suppl. 2015;18:8-15.

30. Gerritsen J, Dekker JM, TenVoorde BJ, Bertelsmann FW, Kostense PJ, Stehouwer CD, Heine RJ, Nijpels G, Heethaar RM, Bouter LM. Glucose tolerance and other determinants of cardiovascular autonomic function: the Hoorn Study. Diabetologia. 2000;43(5):561-70.

31. Standl E, Schnell O, Ceriello A. Postprandial hyperglycemia and glycemic variability: should we care? Diabetes Care. 2011:34(Suppl 2):S120-7.

32. Su G, Mi SH, Li Z, Tao H, Yang HX, Zheng H. Prognostic value of early in-hospital glycemic excursion in elderly patients with acute myocardial infarction. Cardiovasc Diabetol. 2013;12:33.

33. Kuroda M, Shinke T, Sakaguchi K, Otake H, Takaya T, Hirota Y, Osue T, Kinutani $\mathrm{H}$, Konishi A, Takahashi H, et al. Association between daily glucose fluctuation and coronary plaque properties in patients receiving adequate lipid-lowering therapy assessed by continuous glucose monitoring and optical coherence tomography. Cardiovasc Diabetol. 2015:14:78.
34. Kuroda M, Shinke T, Otake H, Sugiyama D, Takaya T, Takahashi H, Terashita D, Uzu K, Tahara N, Kashiwagi D, et al. Effects of daily glucose fluctuations on the healing response to everolimus-eluting stent implantation as assessed using continuous glucose monitoring and optical coherence tomography. Cardiovasc Diabetol. 2016;15:79.

35. Mo Y, Zhou J, Li M, Wang Y, Bao Y, Ma X, Li D, Lu W, Hu C, Li M, et al. Glycemic variability is associated with subclinical atherosclerosis in Chinese type 2 diabetic patients. Cardiovasc Diabetol. 2013;12:15.

36. Su G, Mi S, Tao H, Li Z, Yang H, Zheng H, Zhou Y, Ma C. Association of glycemic variability and the presence and severity of coronary artery disease in patients with type 2 diabetes. Cardiovasc Diabetol. 2011;10:19.

37. Tiftikcioglu BI, Bilgin S, Duksal T, Kose S, Zorlu Y. Autonomic neuropathy and endothelial dysfunction in patients with impaired glucose tolerance or type 2 diabetes mellitus. Medicine. 2016;95(14):e3340.

38. Watkins LL, Surwit RS, Grossman P, Sherwood A. Is there a glycemic threshold for impaired autonomic control? Diabetes Care. 2000;23(6):826-30.

39. Monnier L, Mas E, Ginet C, Michel F, Villon L, Cristol JP, Colette C. Activation of oxidative stress by acute glucose fluctuations compared with sustained chronic hyperglycemia in patients with type 2 diabetes. JAMA. 2006;295(14):1681-7.

40. Costantino S, Paneni F, Battista R, Castello L, Capretti G, Chiandotto S, Tanese L, Russo G, Pitocco D, Lanza GA, et al. Impact of Glycemic variability on chromatin remodeling, oxidative stress and endothelial dysfunction in type 2 diabetic patients with target $\mathrm{HbA1c}$ levels. Diabetes. 2017;66(9):2472-82.

41. Ceriello A, Esposito K, Piconi L, Ihnat M, Thorpe J, Testa R, Bonfigli AR, Giugliano D. Glucose "peak" and glucose "spike": impact on endothelial function and oxidative stress. Diabetes Res Clin Pract. 2008;82(2):262-7.

42. Vincent AM, Russell JW, Low P, Feldman EL. Oxidative stress in the pathogenesis of diabetic neuropathy. Endocr Rev. 2004:25(4):612-28.

43. Feldman EL. Oxidative stress and diabetic neuropathy: a new understanding of an old problem. J Clin Investig. 2003;111(4):431-3.

44. Emanuel AL, Nieuwenhoff MD, Klaassen ES, Verma A, Kramer MH, Strijers $R$, Vrancken AF, Eringa E, Groeneveld GJ, Serne EH. Relationships between type 2 diabetes, neuropathy, and microvascular dysfunction: evidence from patients with cryptogenic axonal polyneuropathy. Diabetes Care. 2017:40(4):583-90

45. Ruiz J, Monbaron D, Parati G, Perret S, Haesler E, Danzeisen C, Hayoz D. Diabetic neuropathy is a more important determinant of baroreflex sensitivity than carotid elasticity in type 2 diabetes. Hypertension. 2005;46(1):162-7.

46. Monnier L, Lapinski H, Colette C. Contributions of fasting and postprandial plasma glucose increments to the overall diurnal hyperglycemia of type 2 diabetic patients: variations with increasing levels of $\mathrm{HbA}(1 \mathrm{c})$. Diabetes Care. 2003;26(3):881-5

47. Tabak AG, Jokela M, Akbaraly TN, Brunner EJ, Kivimaki M, Witte DR Trajectories of glycaemia, insulin sensitivity, and insulin secretion before diagnosis of type 2 diabetes: an analysis from the Whitehall II study. Lancet (London, England). 2009;373(9682):2215-21.

\section{Submit your next manuscript to BioMed Central and we will help you at every step:}

- We accept pre-submission inquiries

- Our selector tool helps you to find the most relevant journal

- We provide round the clock customer support

- Convenient online submission

- Thorough peer review

- Inclusion in PubMed and all major indexing services

- Maximum visibility for your research

Submit your manuscript at www.biomedcentral com/submit
BioMed Central 